\title{
Reflections on the Reform of Training and Teaching for New Employees
}

\author{
Haike Liu \\ State Grid of China Technical College \\ Jinan, China
}

Ying Zhang

Shandong Electric Power Central Hospital Jinan, China

\author{
Queba \\ State Grid Tibet Electric Power Construction Company \\ Lhasa, China
}

\author{
Lulu Wang \\ State Grid of China Technical College \\ Jinan, China
}

\begin{abstract}
The training of new employees shoulders the responsibility of training qualified employees for enterprises and it also plays a critical role in career planning and professional ability improving. However, most of the training methods can't meet the demands of the new employee's development. Therefore, the training methods' reform needs to be carried out urgently. This thesis takes the training of new employees as an example, innovates the training method based on the new employee's great interest in challenges, funny experiences and rewarding. Training methods including "task-driven", "experience-based" and "scenario simulation" have been advised in this thesis. The investigation indicates that the new training methods can enhance the participants' learning enthusiasm, significantly improve the training effect, and help the trainees grasp the required knowledge and skills systematically within a relatively short period and grow to a staff member equipped with qualified basic ability and quality.
\end{abstract}

Keywords-training reform; task-driven; experience-based; scenario simulation;

\section{INTRODUCTION}

The State Grid of China has always attached great importance to the training of new employees. It can effectively improve the enterprise identity and professional quality of new employees in a short time through centralized training. With the gradual promotion of "Internet+" technology and the continuous update of electric power technology, the new employees put forward higher and higher requirements for the training work.

\section{THE NECESSITY OF TEACHING REFORM}

A. The characteristics of new employees decide to carry out teaching reform

New employees usually enter the company directly after graduation from colleges and universities. Most of them are only children of the post-90s generation. They have different temperaments and characteristics compared with former employees. The traditional teaching methods are no longer suitable for their needs. They like to accept challenges, enjoy interesting experiences, enjoy being praised, and have a unique definition of success. Faced with this group, we need to carry out effective training which can promote them to complete the role change and integrate into the actual work as soon as possible. At present, the characteristics of new employees are as follows:

1) The positive and anti-polar working attitude

A famous global human resources consulting firm (Mercer HR Consulting) has investigated the attitudes of more than 2600 American employees towards work and organization, it found that the working attitudes of employees in different times are quite different. Most employees between the ages of 18 and 24 are more likely to engage in innovative activities than those over 25. However, compared with older employees, the new generation of employees is less satisfied with their jobs, as well as their satisfaction and loyalty to the enterprise. On one hand, the new employees do not like to follow the rules and repetitive work. They are more like to devote themselves to innovative, challenging and interesting work; On the other hand, the new employees hold a changing career concept, they are eager to try different career fields, and pay more attention to whether the enterprise can cultivate the "transferable" competitiveness of its employees.

2) They have a unique definition of success

They want to achieve in their career. They want to rely on their own strength and performance to be recognized by the organization and leaders, and they strongly expect to be recognized by society. They are eager for better development opportunities, higher pay, continuous learning opportunities. They hope that their investment in time and energy will bear fruit immediately. New employees are similar to older employees in some needs, but the difference is that they are more proactive and more direct in presenting their ideas and needs to the organization. 


\section{3) They have their own views on authority}

They worship idols, but they despise authority and do not respect and obey their superiors and elders unconditionally. They are willing to rely on hard work to realize their selfworth. They do not blindly respect the boss or elders, and sometimes even despise authority. Their respect comes from whether the boss has good personal accomplishment and leadership ability.

\section{B. Traditional training and teaching methods can't meet the needs of students in the new time.}

The traditional teaching method of theory lacks innovation. In the process of training and teaching, some trainers only talk and talk on the platform, and do not adjust the teaching methods according to the students' reactions. Students are mainly passive to listen, so they can't concentrate for a long time, which leads to the dull classroom atmosphere and poor learning effect. Therefore, the teaching process should not be unilaterally imparting knowledge but should be completed by the cooperation, complementation and co-operation of trainers and students.

In traditional practice teaching, the participation of the students is not enough. Although the practical training course is complete in all aspects of "teaching, learning and doing", but sometimes it is difficult to grasp "learning" because the former part of "teaching" takes a long time and knowledge points are dense, so it is difficult to "doing" quickly, which makes it difficult for students to participate effectively in the classroom and is not conducive to the mastery of technical skills.

Traditional teaching methods can't satisfy the transmission of a large amount of information. Current knowledge is often interdisciplinary, which requires multi-angle analysis and understanding. It is difficult to complete the effective transmission of a large amount of information only through the instruction of trainers. Students are required to actively participate in classroom teaching, actively receive information combined with their own thinking.

\section{GENERAL THOUght OF TEACHING REFORM}

In view of the characteristics of new employee training, we should abandon the traditional mode. The shortcomings of traditional teaching methods are emphasizing too much on the explanation of trainers, insufficient participation in teaching, insufficient time for discussion, insufficient guidance for solving practical problems and practical operation. So, we should determine the needs of students' posts according to the vocational ability training norms of State Grid Corporation, adoption "scene simulation”, “task-driven”, "group confrontation”, "experiential” and other teaching methods to improve teaching mode and the training effect.

\section{A. Do a good job in training needs analysis}

Training needs analysis refers to the process in which trainers adopt various methods and techniques to systematically identify and analyze the learning objectives before planning and designing each training activity, so as to determine the training content. Training needs analysis can be carried out by means of interviews and questionnaires. We can interview with the managers of enterprises to understand the expectations of managers for new employees, and also with the head of the new employee, so as to analyze the training needs from the professional and work point of view. After knowing the expectations of the managers and the head of the department for new employee training, we can carry out targeted induction training for new employees. It can improve the efficiency of training work very much.

\section{B. Guiding students to participate in teaching and interactive communication to enhance the effectiveness of teaching}

We should arrange some discussion or experience exchange in the teaching. It can guide the students to draw conclusions through the discussion or exchange. It can also improve the students' understanding and analysis ability in the group discussion. The trainees found problems and asked questions in the operation. Finding out the problem is the key, only by knowing what is missing can they be interested in learning and actively participate in the teaching process.

In practice training, students can first grope for exercises according to the knowledge they have learned.They can find out errors and the consequences of errors in their own operation. Then the teacher demonstrates the standardized operation process and explains the operation logic. This can deepen the students' understanding of the correct operation sequence and operation logic. Participation in the teaching process through the mode of "doing, teaching and learning" can stimulate students' interest in participating in learning. It can also establish students' inner sense of mission and desire of self-transcendence, promote the improvement of thinking ability, and make learning become the accelerator of students' competitiveness.

\section{Using simulation resources to improve teaching effect}

For newly recruited students, they have theoretical knowledge and a lack of perceptual knowledge of the substance. The power system is a huge and highly connected system. It is impossible for students to operate in the actual power system. The same effect can be achieved by using advanced simulation technology to simulate the operation in training. In the practical training of substation operation and maintenance, by simulating the normal, abnormal, fault conditions and corresponding phenomena of the substation, the trainees can have an intuitive understanding of various working conditions. In the practical training of switching operation, the trainees can first operate according to their own understanding, observe the occurrence of accidents, then discuss and analyze the causes of accidents, so as to enable the trainees to have an intuitive understanding of various working conditions. At last the teacher instructs the students to operate in the correct order to deepen the understanding of the correct operation logic.

\section{Group discussion teaching}

Before class, the trainer gives students the preview outline and some questions, lets the students preview the new knowledge. In class, the trainer lets students carry on the discussion in group aims at the question in the preview outline, and then ask some representative to express their point of view. The classmate carries on the appraisal, and also the trainer 
carries on the appropriate instruction and the prompt, at the same time the trainer raises different depth questions for the different level student. Finally, the students summarize what they have learned in this class. In this form of teaching, the pre-class workload of teachers is very large, and the quality of preview outline directly affects the various rings of teaching section, affects students' interest in learning, learning habits, learning ability. The trainer should set up preview outline according to the characteristics of the subject. They should set up basic knowledge, typical examples, classroom detection, homework considered at high, medium and low levels students. After class, the teacher should reflect on the use of the discussion case before class and in class, and record it in order to further correct and perfect the discussion problem and case.

Implementation case: six people are a group, of whom two are top students, two are middle-class students, and two are poor students. One of them sits at the same level opposite the desk for discussion. Each group set up a team leader, the team leader is not necessarily the best learning but must be the most enthusiastic, and management ability is the strongest. Train team leaders give full play to the management, and organization of the team. The trainers should innovate the evaluation mechanism of the group, use the appropriate evaluation to train the group to think actively, study deeply, study efficiently, and turn the evaluation into the additive of a class.

\section{E. Simulating on-site working situation and task-driven teaching reform.}

Integrating knowledge and skills with on-site work process as the mainline to form a ladder curriculum system that conforms to the law of ability development and career growth. The training method and process are designed according to the requirements of vocational posts by using the integrated training mode of doing, teaching and learning. It can strengthen the training of students' abilities, enhance their professional abilities, and achieve the training effect of mutual penetration of theory and practice by using the ladder curriculum system. In the "teaching" module, The trainer teaches or demonstrates cases related to the training content. The trainees can enhance their perceptual awareness of the importance of knowledge, stimulate their interest in learning, and change their mentality from "you want me to learn" to "I want to learn". In the "learning" module, the trainer trains the students' ability through questioning guidance, organizing group discussions, analyzing methods to solve practical problems. The trainees' designs operation steps to complete various tasks. In the "do" module, students are grouped into groups to operate. The trainer clarifies the form of group division of labor and cooperation among members. Each member completes different tasks in different identities. The students' learning ability, method ability and the ability to solve problems independently are trained through learning and practicing the operation content,

Design example: substation operation and maintenance major "220kV smart substation switching operation"

\section{1) Pre-class preparation}

The total number of students for this training course is about 16. Before class, the students are divided into two groups of $\mathrm{A}$ and $\mathrm{B}$, each group of 8 people, the desks are put in the form of two discussion groups. Each of the two trainers is responsible for a group of students.

\section{2) The scenario mode introduces}

The simulated scene scenario: the supervisor of the substation receives the dispatching order at 8:20 on 6 July 2015, " smart line I switch of $220 \mathrm{kV}$ smart substation operates from operation to overhaul at 10:05", "The smart I-line switch of $220 \mathrm{kV}$ smart substation is changed from overhaul to operation at 11:05".

\section{3) Simulated training}

A) The two groups discuss the safety matters needing attention, the arrangement of safety measures and the operation steps of switching operation respectively according to the working task,

B) The selection representatives of the two groups reported on the results of the discussion, and then the two trainers commented on the participants.

C) The trainer explains the normal process of switching operation and the normal term of switching operation.

D) Group A students select monitor, guardian, operator and dispatcher to perform simulation of switching operation practice. After the exercise, Group B students comment on the simulation operation of Group A students.

4) Field switching operation training

Two trainers lead the two group students to carry out the training of switching operations.

\section{5) Summary}

The trainers summarize the training courses and evaluate the comprehensive performance of the two groups.

\section{F. Role-playing experiential teaching}

Experiments show that in learning, the knowledge of reading can be remembered by $10 \%$, the knowledge of hearing can be remembered by $20 \%$, and the knowledge of personal experience and experience can be remembered by $80 \%$. Experiential teaching is a powerful, effective and influential teaching method. It is a process of direct recognition, acceptance, respect and application of knowledge and ability. Experience comes from personal experience. It will be profound and unforgettable for life. The essence of experiential teaching has the following main characteristics: learners are aware of the learning and process that is taking place. Those experiences and contents are of unique personal significance. Learners are wholly engaged.

For example, when the students carry out the watt-hour meter verification, the trainer explains the problems that are easy to appear in the process of watt-hour meter verification and the measures to deal with the common problems to the students. And then The trainer let the three students act as the user, the staff and the manager. The user asks the staff to check the basic error, standard deviation and start-up test of the meter. The manager and the user watched carefully and saw if there are any errors in the check. If they find an error, they will be deducted 100 Yuan from the staff's salary, and finally, the trainer compares who received the most salary. It 
can improve students' sense of responsibility and cultivate students' serious work attitude through the group practice of role-playing.

\section{G. Case teaching method}

The case teaching method is first applied to the field of law and then applied to the field of management. Now it has been introduced into the field of vocational education. It is a teaching method in which the trainer organizes students to discuss and study the case given by the trainer. The cases are chosen according to the needs of teaching objectives and contents. The purpose of case teaching is not to train students to be "theoretical masters" who can only explain problems, but to train students to have "wise masters" to solve practical problems and to solve the problems of "how to do" and "what to do". In the case of teaching, trainers and students bear more responsibility for teaching and learning and require more input and participation. The trainer has the responsibility to select and organize the materials to be discussed, he has to select the appropriate cases from a large number of materials, and if there are no ready-made cases that can cover what he taught, he has to write these cases himself and present them in a certain procedure. As far as students are concerned, he also bears a certain responsibility to analyze and discuss the specific facts and original materials provided by the trainer. For example, the trainer takes the safety education class; he could select some representative cases of safety education for student analysis, such as the safety accident caused by the incorrect arrangement of safety measures, the safety accident caused by the operation of no operation ticket, and so on. The students can express their own views that can cultivate their ability to analyze problems. The most suitable number of people in Case teaching is about 15 because it can be a full exchange of views, the solution to the problem can be fully discussed.

\section{H. Establishing a perfect training effectiveness evaluation system}

Training effectiveness is an important means to measure the effectiveness of training. We can summarize the good experience in the implementation of training organizations and find out the problems and shortcomings through the evaluation of training projects, then put forward continuous improvement suggestions, so as to make training more targeted and improve the effect of training. We used Kirkpatrick's four-level model evaluation method in our training. These four levels are reflection, learning, behavior and result. The first level is mainly through questionnaires and oral inquiries, asking the students to evaluate the course content, the trainer's teaching skills and the overall teaching effect. The second level is learning. Students' mastery of knowledge and skills is understood through written examination and skill operation examination. The results of the examination are analyzed within ten working days after the completion of the examination; the situation of students' knowledge mastery is obtained and submitted to the curriculum development department to optimize the curriculum design. The third level is behavior. We can find out the extent and performance of the trainees' work behavior through questionnaires and observation. The fourth level is the effect. We can understand the influence of behavior change of trainees on colleagues and organizations around after training through the analysis of accident rate and productivity.

\section{SUMMARY}

The electric power industry needs a large number of skilled talents. They should not only grasp solid basic theoretical knowledge but also have strong practical ability and certain professional practical experience. They should be able to analyze and solve problems better in practical work and have high comprehensive quality. After the teaching reform, there is no longer single preaching in teaching, but a variety of teaching methods, which are guided by teachers and gradually. Trainees actively participate in the completion of work tasks. The teaching methods such as teaching, learning and doing are intertwined together, and multimedia courseware teaching, trainers adopt the integrated training mode of doing, teaching and learning to design the training process, and change the traditional "passive classroom listening" into "on-site automatic attempt", so that trainees can fully integrate theoretical knowledge and professional skills through practical training, master various operational skills, and be familiar with their professional posts. The trainers provide the students with practical opportunities as much as possible to ensure the consistency of learning and work, which fundamentally stimulates the students' interest in learning and learning autonomy, and improves their post adaptability and professional quality. Practical training and simulation technology is adopted to fully mobilize students' interest in learning. The satisfaction rate of students' comprehensive evaluation course reaches $97.8 \%$, forming a harmonious scene in which teachers are willing to teach and students are happy to learn.

\section{REFERENCES}

[1] Ilhami Arseven. "The Use of Qualitative Case Studies as an Experiential Teaching Method in the Training of Pre-service Teachers”, International Journal of Higher Education, January 2018, Vol. 7, No. 1; 2018.

[2] Maheshkumar P. Joshi, Elizabeth B. Davis, Ravi Kathuria, C. Ken Weidner, II. "Experiential Learning Process: Exploring Teaching and Learning of Strategic Management Framework through the Winter Survival Exercise”. June 2015.

[3] Srinivas Bangalore, Giuseppe Di Fabbrizio, Amanda Stent. "Learning the Structure of Task-Driven Human-Human Dialogs” IEEE Transactions on Audio Speech and Language Processing • July 2006.

[4] Fengyun. Li, "To explore effective training methods for electric power producers”. China Journal of Electric Power Education. April 2010. (In Chinese)

[5] Jinhua Zhang. “A summary of experiential teaching research". Heilongjiang higher Education Research. June 2010. (In Chinese)

[6] Yuqing. Liu, "Research on using Simulation Resources to improve training effect”. China Electric Power Education. April 2010. (In Chinese) 